\title{
A Data-Driven Model of Language Teacher Autonomy in Iran's Public Schools
}

\author{
Nasimeh Nouhi (Corresponding author) \\ Department of Foreign Languages and Linguistics, Shiraz University, Shiraz, Iran \\ E-mail: nnoohij1985@gmail.com \\ Seyyed Ayatollah Razmjoo \\ Department of Foreign Languages and Linguistics, Shiraz University, Shiraz, Iran
}

Received: 01-10- 2014

Accepted: 26-12- 2014

Advance Access Published: January 2015

Published: 01-05- 2015

doi:10.7575/aiac.ijalel.v.4n.3p.159 URL: http://dx.doi.org/10.7575/aiac.ijalel.v.4n.3p.159

\begin{abstract}
The present article tries to come up with a model of teacher autonomy in Iran. The study uses grounded theory approach to develop a model out of the data collected. The participants of this study are 20 experienced language teachers who in Iran public schools. Purposive sampling procedure has been used to select those teachers who are as representative of the population as possible and serve our purpose well. The participants were interviewed using two procedures. One was focus group and the other was individual interview. Their interviews were recorded and then transcribed. The codification phases of grounded theory including open, axial and selective codlings were applied. Each phase led to some categories which then were subsumed under bigger categories in later phases. In the last phase the model developed. "Tradition" and "regulation" were two main components of the model which affect language teacher autonomy in Iran. "Personal features" was another component of the model which acts as a mediator meaning that it can affect the way the two other components mentioned. This model is a context-sensitive one and can be applied in different setting to identify factors that hinder or facilitate language teacher autonomy.
\end{abstract}

Keywords: language teacher autonomy, grounded theory, Iran

\section{Introduction}

"Learner autonomy" has already gained grounds in the teaching profession. But, "teacher autonomy" is almost a new concept that is mostly advocated by post method pedagogues. In Greek history the word "autonomia" was present and defined as "when citizens were governed by laws of their own making, rather than by laws or force of a foreign or conquering power".

A cursory glance at the literature on teacher autonomy leads to no straightforward definition of teacher autonomy. Different authors have defined it in different terms. Some perceive autonomy as isolation, some may think of autonomy as gaining liberty from interference or supervision and some other may point to it as the freedom to develop collegial relationships with others and the authority to perform tasks and activities.(Fraser \& Sorenson, 1992). Every teacher, especially language teachers, needs some degree of autonomy to be an effective teacher. Otherwise the teachers will be merely a practitioner. Teachers need to have some freedom to exercise their teaching cognition, set their own goals, plan the procedures, act the plans and see the results. The accumulation of these acts will lead to enrichment of their teaching and also their professional development. Education systems and institutes differ in the degree that their teachers enjoy autonomy. Some education systems allow some degree of autonomy to teacher; so, they can have a say on what to teach and how to teach and evaluate their teaching material. However, there are other education systems which do not offer the least autonomy to their teachers. They are heavily centralized and controlled and everything is set a priori. And there are so many education systems that seek the middle ground. The language teachers working in an educational institute, whether public or private, can gauge the status of autonomy they are granted and the factors that can facilitate or inhibit the exercise of autonomy. The status of language teachers' autonomy in Iran has been underresearched. This study aims to investigate the status of language teacher autonomy in Iran's public schools. Iran's public school is a centralized system in which the textbook, the curriculum and some part of evaluation process are already set and are offered to teachers in pre- fabricated packages. Although centralized curriculum restrict the amount of autonomy that teachers may have over their teaching there are lots of other factors that may play some roles in granting or withdrawing autonomy to and from teachers. This study tries to come to a model that can fully represent and account for those factors. For this to happen a large and comprehensive amount of data from the very people involved in the study is needed to ensure that the model is data-driven. Grounded theory approach is used to develop such model. The data are collected from language teachers. Although the model is going to be developed out the data collected in Iran public school context, it is hoped that the data driven theory developed in this study can be comprehensive enough to serves as a model to investigate the factors that facilitate or inhibit the exercise of autonomy in any education system. This work is significant because it tries to identify factors which are determinant in the amount of autonomy that 
language teachers have. The aim is to come to a broad comprehensive view of these factors and not just factors internal to the education institute.

\section{Literature Review}

The literature on teacher autonomy has several definitions and interpretations of teacher education practices. Some researchers have taken a political stance in which they regard the sociopolitical and institutional factors like (Einolf, 2002) and others like Parr (2006) and Smith (2006) take a more psychological account which means they try to locate the internal factors which account for autonomy of language teachers. So many studies have been done which try to analyze the relationship and effect of teacher autonomy and learner autonomy (e.g. Charters, 1976; Chauvin \&Ellett, 1993; Forsyth \& Danisiewicz, 1985; Friedman, 1999).Still, other empirical researches have investigated the relationship between teacher autonomy and other variables like motivation, job satisfaction, teacher empowerment and teacher burnout (Brunetti, 2001; Kim \& Loadman, 1994). Some authors hold different views regarding what the concept of autonomy is. To Fraser \& Sorenson (1992) "To be isolated in a classroom without collegial interaction or meaningful feedback is not the intended spirit of autonomy" (p. 40). This categorization of the domains has been the main one in the teacher autonomy literature. A plethora of research focuses on the constraints on the exercise of autonomy by language teachers in the education systems.

Ramos (2006) in his research on "Consideration on the role of teachers" (p. 192) pointed to four main constrains which he called as handicaps. The first one is "fear of change". One may not dare to try new things but prefer to go for the same safe procedures. The second one is the fear to release teacher's control. The empowerment of students through the exercise of power balance in the classroom is something many teachers are not ready to foster. The third source of constraints comes from educational authorities, governmental or organizational institutions that leave little room for teachers' personal and professional development. The fourth constraint is within teachers themselves, their attitude. Their resistance to invest time, effort and money in their own personal and professional development and growth is the reason why they would like to stick to old practices, experiences, materials and habits instead of trying new things. This negative attitude may keep teachers behind of their knowledge, skills, influencing learners ${ }^{\text {ee }}$ results (cited in Thu 2011, p.25). These lines of research were the most prominent ones on teacher autonomy. The next section deals with the methodology of the research.

\section{Method}

To come to a clear picture of autonomy in an education system, the data should come from the very education system including the people involved, the culture of that education system, etc. Hence, the current study is qualitative design to ensure a clear picture and comprehensive view of the entity. The study uses grounded theory approach and constant comparative as the main procedures for data analysis.

\subsection{Participants}

The participants of the study are language teachers who have at least 10 years of experience and are still working in the system. They are selected based on purposive sampling. An attempt was that those language teachers who are representative be chosen.

\subsection{Instruments}

The main instrument of this study was in-depth open ended interview with the language teachers. The interviews aimed to make the participant familiar with the nature and the scope of the study, and to attain a deep account of the participant's feelings, experiences, thoughts, ambitions and interpretations. Interviews continued until saturation was reached. Some were interviewed individually and some were interviewed in a focus group in order to enable them to propose their ideas on teacher autonomy challenge others' views and defend their own views. The participants were assured confidentiality in the process of the data collection and report. In this way a wealth of data was collected. First, they were asked to provide a definition of teacher autonomy. Then, they were asked to gauge the status of language teacher autonomy in Iran's public schools. They were also asked to provide the factors that may hinder or facilitate practice of autonomy by language teacher and why some teachers feel more autonomous and some do not.

\subsection{Procedure}

The participants were selected based on purposive sampling meaning those teachers who were considered as representative of the population were selected. Some factors like years of experience were taken into consideration in the selection process. They were interviewed and the data was recorded and then transcribed. The data were coded to identify the factors that contribute to or hinder autonomy of language teachers in Iran. The data was then analyzed through the application of the first stage of grounded theory approach which was open coding. This procedure entails a line-by-line analysis and searching for words, phrases, names, accounts and sentences that denote some concept or meaning. This stage leads to identification of basic recurring concepts and categories and themes. These found concepts and categories were the subject of more analysis with new data from other teachers. The two other stages include axial coding and selective coding. The coded data resulted from the open coding stage was analyzed and coded to form larger categories. In selective coding which is the final stage the resulted coded categories are further coded to form the themes which are the building blocks of the model. In all phases the new data informs the previous. And the previous data is constantly compared to the new data. 


\subsection{Standards of rigor}

The coded interviews were sent back to the participants to ensure that their views were well represented and no bias had affected the analysis of the data.

\section{Data Analysis}

Ary et al. (2006) in their book define data analysis as: "Data analysis is a process whereby researchers systematically search and rearrange their data in order to increase their understanding of the data and to enable them to present what they have learned, to others"(p.489) The first step for the researcher was to get familiar with the data. She read the data several times to get acquainted with the participants' general views on autonomy. The next step was codification.

\subsection{Codification of the Data:}

Codification is the core of grounded theory approach and includes the identification of categories and going to larger categories. In this respect, Wiresma (2000) stated that: "Coding is analogous to getting ready for a rummage sale: you sort the sale into categories" (p.203.)

After initial reading of the data, the researcher coded the collected data based on the stages presented by the grounded approach theory which are, open coding, axial coding and selective coding (Glaser \& Strauss, 1967; Strauss \& Corbin, 1998). Accordingly, these steps are referred to as pieces of data, categories and themes by Ary et.al (2006). The following section of this study is arranged and presented based on the above mentioned stages.

\subsubsection{Open coding}

This step involves reading and rereading the collected data. In doing so, the instants of events, attitudes, feelings, points, ideas, thoughts, behaviors and experiences which are repeated several times are identified and coded. The researcher came to a wide range codes in this step. Some of these codes were reduced later. Various factors that contribute to or hinder language teacher autonomy were mentioned by the participants. In this study several codes came to surface. Here the researcher will present some pieces of the participants' comments.

One recurrent factor hindering language teacher autonomy was "peer pressure"; that is, how other colleagues react to a teacher who acts differently and tries to do something that is different from what is already prescribed. Some participants pointed to the experiences that they had when they tried to implement a new method in teaching. One of them said:

"You get adapted to the system. This is what happened to me my methodology was much liked by the students and partially by the principals. But I realized that some of my colleagues were frowning upon my practices. To them especially to those with 20 or more years of experience they did not welcome this they said it's not what a classroom should look like, the students should sit in rows and columns not in group, they were free to move their seats and go to other groups. After a couple of month I did away with this. Because gradually the rest of the colleagues joined those older ones complaining or criticizing or giving pessimistic comments then I shifted to technology, I moved to another strategy, I took students to laboratory each session and being praised for my new strategy on the part of the manger, this was also a source of jealousy, the rest of the teachers made it difficult for me to reach the laboratory, having their students there and watching movies instead. They looked at me as outcast. Although in person when they were talking to me they were very friendly but through connections I found that those hindrances were intentional. Now I stick with the traditional methodology. I feel very tired of the school. Previously I enjoyed my cases."

Other teachers perceived such a teacher who tried to change the routine methodology as a threat. They felt that they will be compared to those teachers and will be thought of as working or caring less by their mangers. So, they wanted everyone to be like them. They could tolerate no innovative teacher.

Another factor that in teachers' view can affect language teacher autonomy is "education level of teachers". Those teachers holding higher degrees in their field reported to be more autonomous and granted more room to act autonomously by the school principals or other superior ranks. Their degree gave them some power and authority to have a voice, their view be accepted well and their acts be more justifiable.

"Being a PhD student gives me the power to do almost everything that I like to do. Things I can do are not like what I could do 5 years ago because I was a B.A student. Then I turned to be an M.A student and I had more freedom. Now that I'm a PhD student I have lots of freedom. The teachers believe in my authority and sometimes I'm asked to judge other teachers but previously I was judged although I was more proficient."

Several similar experiences and ideas were mentioned by teachers.

Some rare cases pointed to was the socioeconomic level of the teachers as a factor that can affect the amount of autonomy that a teacher can enjoy.

I think different factors play different roles even the financial status of the teacher. A teacher who drove Peugeot which was a wealthy car then had lots of freedom so wealth status had an impact on the amount of power that you will have. 
Another factor that was raised by the participants was the "value system" or mentality of the teacher. It was believed by some participants that teachers differ in their beliefs and attitudes which in turn affect how much they feel autonomy is needed or practice autonomy.

Actually first I define and categories autonomy to 2 categories values that the teachers should have and the procedure. In terms of values, a teacher who is autonomous sets her own values. And the second part how to implement the values that you have in mind. I myself try to be autonomous all the time. ex.: in my values who is a good student. For example to me a good student who is silent is not a good student or a student who only does studying and does no other thing isn't a good student. I look at students as well-rounded students, a person who is adept in different skills in terms of communications, in terms of studies. In terms of procedures all of the time, I try to have my own procedures. In testing for example whenever I see that my students are week I only teach some parts of the book not all parts. or if they have a centralized exam I stick more to the syllabus mostly my class due to situation that I have half of my class go to issues related to ethical issues, being familiar with students and their problems and talk to about different social issues and how they can find their way out in their lives. Based on my values I think we should try to be good citizens not just good students, I mean whole persons. And most of the time the managers are not satisfied with the procedures whenever your class is too noisy but I personally I don't pay attention to the mangers.

"Assessment" can be an important factor that hinders language teachers' autonomy, as mentioned several times by the participants of the study. This "assessment" can take two forms. One is the annual evaluation made of teacher by the school principal and the other is accountability to the final exams and to have a proper level of pass rate. Both these issues affect the amount of autonomy that language teachers may have. The teachers feel that they have to conform to what is wanted of them. There is no room to teach and evaluate their students in their own way. They have to follow a specific methodology that leads to better assessment results which is what is wanted of them by the superiors. They feel that they have to conform to the regulations if they are to be judged as a good teacher.

"One deterrent in being autonomous is the issue of accountability in terms of high stake testing. You see university entrance examination overshadows the way we behave in classes"

Another interesting factor that has a bearing on teacher autonomy is the age and level of the learners. The teacher participants thought they felt to be more autonomous and act more freely with the students of lower level proficiency and of younger age.

I think for below average students, autonomous teachers prove more effective. U know the other day I asked my friend who is studying geochemistry in Shiraz University he is doing his PhD. I asked him to come to the class and do some team teaching. It was theology class but I asked him to talk about science. And the way he taught science, although my students are very low in average compared to other schools, but he improvised and designed his teaching in an innovative way. He attracted all the students, even the students who were known to mess the classroom always. And the students went to office and asked him to come to class again. I mean autonomous teacher works for lower students better.

"Centralized curriculum" was another repeatedly-mentioned factor. The teachers believed that since everything is set beforehand they have no room to be creative and act based on their own teaching cognition.

"The centralized curriculum is already set for the teachers, as an autonomous teacher, as a partially autonomous teacher, I try to adapt the textbooks. Adapt the resources let's say. I do not treat the resources as scripts to be followed strictly I treat them, as resources. I make some changes"

Another factor that teachers mentioned was the bureaucratic requirements including "circulation", the official orders that are circulated and the dos and don'ts are set for the teachers. These circulations can be related to educational factors or other institutional factors. The teacher felt that so many of the things that are related to them are prescribed and set for them; even some personal affairs like how they should dress at schools.

"Even our way of clothing like wearing jeans is problematic. If I was autonomous I would have the permission to wear jeans."

"Conformity to the norms of society" was another factor mentioned by the participants.

"I think the milieu we are in, the general script or the ethos, as members of a collectivist society make it hard to practice teacher autonomy. You see, what the norm is and practiced is when in Rome do as Roman do. This is the norm in our school even in the school of exceptional talent where I teach."

"But I think it is not possible because in the philosophy of education, an author believes that when in an educational system the aim is indoctrination, you cannot talk about teacher autonomy or learner 
autonomy or critical sort of teaching. I think these are something unimaginable. Indoctrination is important.

Some participants turned to broader cultural issues as factors related to language teacher autonomy. One of the participants mentioned:

The famous French sociologist refers to the effect of the habitués. Our habitués I mean Middle East and especially Iran doesn't allow us to be autonomous in any field especially in teaching"

Another one added:

"You can think of hierarchy. At the top level you have authorities which decide everything for those below level one. The same goes with the father of the family. He dictates everything in the family but he talks about freedom and democracy. Then the same goes with the students and the teachers. This culture of autonomy is not prevalent in our society from top to toes.

In this first phase which was open coding, several recurrent items were identified as factors contributing to or hindering language teacher autonomy including: peer pressure, centralized curriculum, teachers' education level, values and socioeconomic status, assessments, pass rates, conformity to society circulations, etc. However, these discreet items would lead nowhere by themselves. To be more conclusive and to be closer to a theory out of the data gathered a further step was needed, namely, axial coding.

\subsubsection{Axial Coding}

Strauss and Corbin (1998) described axial coding as "the process of relating categories to their subcategories ... linking a category at the level of properties and dimensions" (p. 123).The open coding leads to development of some codes. The pieces of data that were on the same topic were brought together and a concept was formed. An analysis of the codes identified in the open coding leads to more conclusive concepts to come to surface. Some categories seem to be related and point to the same issue.

Teachers' education level, teachers' socioeconomic status, teachers' values are all factors related to language teachers involved in teaching practice. So the first concept that appears is teacher characteristics.

Learners' age and proficiency level were identified as contributing or hindering language teacher autonomy, hence, they can be grouped to develop a larger category named learners' characteristics. So the second concept is learners' characteristics.

The codes identified in the first phase of the study including, annual evaluation of the teachers, accountability to exam results, pass rates all share an element of institution factors. So the third concept can be named as "institution factors".

Centralized curriculum and bureaucratic requirements including circulations were pointed to by the participants as factors affecting the practice of autonomy by language teachers. All these factors can be merged in to form a more general group. The gist of these codes can be named as "education policy" factors.

The "colleague pressure" and "school type" were all related to a concept which can be called "school culture". And the last, but not the least, is factors related to societal factors and cultural norms. This category includes other subcategories like collectivistic society and conformity to the general society which are the two features of our society. This category encompasses a large proportion of factors affecting language teacher autonomy.

At the end of the second phase of codification six concepts were identified that were assumed to contribute or hinder language teacher autonomy in Iran. These categories which are the result and amalgamation of the codes identified in open coding include: teachers' characteristics, learners' characteristics, institutional factors, education policy factors, school culture the larger cultural norms. These categories help us have a broader view of the status of language teacher autonomy in Iran. However, the theory is yet far from being developed. For this to happen, a further step is needed to be taken; namely, selective coding.

\subsubsection{Selective Coding}

The last phase in codification of data is selective coding that is assigning the categories defined so far to larger category or as Aryet al. (2006) put it "themes".

This final stage of data analysis in grounded theory builds upon the foundation of the previous open and axial coding efforts. Selective coding is "The process of selecting the central or core category, systematically relating it to other categories, validating those relationships, and filling in categories that need further refinement and development" (Strauss \& Corbin, 1990, p. 116).Strauss and Corbin (1998) stated that this central or core category should have the analytic power to "pull the other categories together to form an explanatory whole" (p. 146).This final stage will lead to developing a theory which is the final aim of grounded theory approach.

Having a look at the codes and concepts identified in the two previous phases of codification, three broader and more comprehensive themes are evident. The accumulation of these three themes forms a theory of the factors that contribute to or hinder language teacher autonomy in Iran. 
The institutional factors and education policy factors all are about the rules that are set by the larger institute or education setting. The teachers are required to follow and comply with these rules. They are mostly written and nationwide requirements. So, the first theme is the "regulations".

On the other hand, social factors and cultural norms are not neatly written regulations but they are the norms that are set and are affected by the larger society and culture in which the education institute locates. This includes people, norms and shared knowledge and experiences that a group of people have; whether a small group like a school or a larger one like a society. A thread that runs unfailingly through all these categories is "tradition". Although they are not written down, it is believed that they are more powerful. They act as pressure forces which can contribute to hinder language teacher autonomy. So, the second theme is "tradition".

Teachers' characteristics and learner characteristics are all personal attributes of two main groups of people involved in the practice of teaching. All these factors in a way contribute or hinder language teacher autonomy in the view of the participants of this study so all of them can be categorized in a more general category named "personal features".

In this study the larger categorization that is considered for this phase is classifying the categories emerged from the second phase into three more comprehensive concept or themes as "tradition", "regulation" and "personal features".

\section{Conclusion}

The themes developed in the codification phases give us a clear picture of the factors that inhibit or facilitate the practice of autonomy by language teachers in Iran public schools. We are now in a position to accumulate these themes and develop a model that can account for teacher autonomy in Iran. The model can be presented in figure 1:

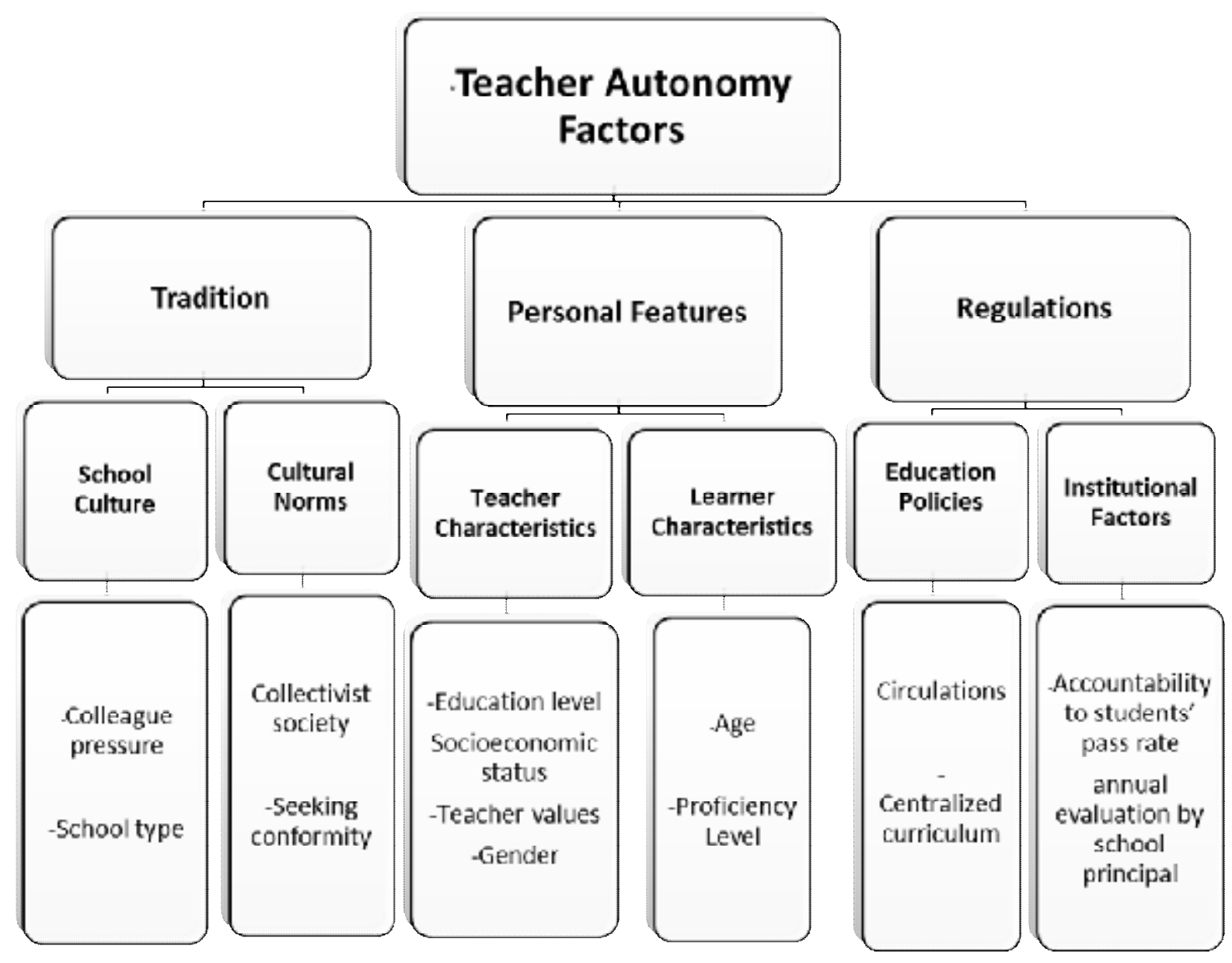

Figure 1. A model of language teachers' autonomy

This model is driven from the viewpoint of the teachers involved in the teaching practice. So, every item has a say on the amount of autonomy that language teachers may enjoy. These components of the model stand as items to be checked to see whether they are present.

The two dominant components of this model are tradition and regulation. Tradition includes the setting and atmosphere in which one lives or works, the accumulation of our past shared understanding and our unique way of thinking and culture which is distinguishable from other context. It is much dependent on the people which live in that context.

The other main component is the regulation which encompasses the bureaucratic requirements that are obligatory and the teachers and the school staff have to abide. They are mainly set by stakeholders in the education ministry. These two components are specific for any society and education system. They have to be identified as factors affecting language teacher autonomy. Some of these factors were identified in the specific context of Iran. These two components are largely constant. Although teachers may have some influence, they are not in control of teachers. 
Personal features act as mediator. The personal features work as variables which can take different values which in turn affect how much a language teacher may feel autonomous. They can affect the way that the two other components work. For example gender as a personal feature has a mediating role in the sense that female participants of the study were more sensitive to school culture. They felt to be more or less autonomous if the school culture or climate seemed positive or negative to them. So personal feature of the people involved in the education institute the practice of autonomy may differ. Another instance might be "education level" of the teachers which may influence how much the language teacher feels forced to abide the regulation.

This model can be applied in different education context. Once the variables and factors hindering and contributing autonomy are identified, it will be easier to help the teachers have more autonomy in the current education system.

\section{References}

Akbarpour-Tehrani, I. \&WanMansor, WFA. (2012). The Influence of Teacher's Autonomy in Obtaining Knowledge on Class Practice. Procedia - Social and Behavioral Sciences. V66: 544-554. Elsevier.ISSN $1877-0428$. http://dx.doi.org/10.1016/j.sbspro.2012.11.299

Allwright, D. (1990). Autonomy in language pedagogy.CRILE Working Paper 6. University of Lancaster: Centre for Research in Language Education.

Wolff, R. (1970). In defense of anarchism. New York: Harper and Row.

Arkott, A. (1968). Adjustment and mental health.New York: McGraw-Hill.

Ary, D., Jacobs, L. C., Razavieh, A.\& Sorensen, C. (2006). Introduction to research education( $7^{\text {th }}$ ed.). California: Thomson.

Batey, M. V., \& Lewis, F. M. (1982).Clarifying autonomy and accountability in nursingservices: Part 1.Journal of Nursing Administration, 12(9), 13-18.

Benson, P. (2000). Autonomy as a learners' and teachers' right. In Sinclair, McGrath \& Lamb (eds.), 111-117.

Brown, J. R. (1996). Why do teachers leave? (Master's thesis, University of Toronto.Masters Abstracts International, $35(01), 20$.

Brunetti, G. J. (2001). Why do they teach? A study of job satisfaction among long-term high school teachers.Teacher Education Quarterly, 28(3), 49-74.

Deci, E. L. \& R. Flaste (1995).Why we do what we do: The dynamics of personal autonomy. New York: Grosset/Putnam.

Einolf, A.N. (2002). A study of teacher autonomy in charter school.Doctoral Dissertation, Virginia Commonwealth University.

Friedman, R. (1999). Teacher-perceived work autonomy: The concept and its measurement. Educational and Psychological Measurement, 59(1), 58-76.

Fraser, L. E., \& Sorenson, L. (1992). Teacher motivation and satisfaction: Impact on participatory management. NASSP Bulletin, 76, 37-43.

Gilligan, C. (1982). In a different voice.Cambridge, MA: Harvard University Press.

Glaser, B. G. and A. L. Strauss (1967).The discovery of grounded theory, Strategies for qualitative research. New York: Aldine.

Gonzalez, L. W. (1989). Professional women's perceived autonomy related to autonomous behavior among nurses and teachers. (Doctoral dissertation, Texas Woman's University, 1989).Dissertations Abstracts International, 50 (11A),3767.

Hughes, M. (Ed.). (1975). Administering education: International challenge. London: Athlone.

Kim, I., \&Loadman, W. (1994).Predicting teacher job satisfaction.Columbus: Ohio State University. (ERIC Document Reproduction Service No. ED383707)

Klecker, B. J., \&Loadman, W. E. (1996a, February 23). A study of teacher empowerment in 180 restructuring schools: Leadership implications. Paper presented at the annual meeting of the American Association of Colleges for Teacher Education, Chicago.

Klecker, B. J., \&Loadman, W. E. (1996b).Exploring the relationship between teacher empowerment and teacher job satisfaction.Paper presented at the annual meeting of the Mid-Western Educational Research Association, Chicago. (ERIC Document Reproduction Service No. ED400254)

Lamb, T.E., and Reinders, H. (2008). Learner and teacher autonomy: Concepts, realities and responses. Amsterdam: John Benjamins.

Little, D. (1995). Learning as dialogue: The dependence of learner autonomy on teacher autonomy. System 23.2, 175182.

Maslow, A. H. (1954). Motivation and personality. New York: Harper and Row.

Maykut, P., \& Morehouse, R. (1994). Beginning Qualitative Research: A philosophical and practical guide. London:

The Falmer Press.

Perason, L.C. \& Moonmaw, W. (2005).The relationship between teacher autonomy and stress, work satisfaction, empowerment and professionalism. Education Research Quarterly, 29(1): 37-53.

Myers, D. A. (1973).Teacher power: Professionalism and collective bargaining.Lexington, MA: Lexington Books.

Parr, K.M. (2006). Pre-service teachers' interests and pedagogical judgments.Master'sThesis, University of Florida.

Ramos, R.S. (2006).Considerations on the role of teacher autonomy.Colombian Applied Linguistics Journal,8: 184-202.

Rosenbaum, A. S. (1986). Coercion and autonomy. New York: Greenwood. 
Seidman, I. E. (1991).Interviewing as qualitative research: A guide for researchers in educationand the social sciences. New York: Teachers College Press.

Short, P. M., \& Rinehart, J. S. (1992). School participant empowerment scale: Assessment of level of empowerment within the school environment. Educational and Psychological Measurements, 52, 951-961.

Smith, R.C. (2003). Teacher education of teacher-learner autonomy. In J. Gollin et al. (Eds.),Symposium for language teacher educators: Papers from three IALS symposia (pp. 1-13).

Edinburgh: IALS, University of Edinburgh. Available at: http://www.warwick.ac.uk/ elsdr/Teacher_autonomy.pdf

Smith, R.C. (2006). Developing teacher-learner autonomy: Constraints and opportunities in pre-service training. In Proceedings of the Canarian Conference on Developing Autonomy in the FL Classroom, ed. Bobb-Wolff, L., and Vera Batista, J.L.La Laguna, Spain: University ofLa Laguna.

Strauss, A., \& Corbin, J. (1998). Basics of qualitative research: Techniques and procedures for developing grounded theory (2nd ed.). Thousand Oaks, CA: Sage.

Thu,P. (2011). Effectiveness of student teachers' autonomy in "tutoring program in 2010". Retrieved from: www.scribd.com

Ulriksen, J. J. (1996). Perceptions of secondary school teachers and principals concerning factors related to job satisfaction and job dissatisfaction (Doctoral dissertation, University of Southern California, 1996). Dissertations Abstracts International, 58 (01A), 0127.

Willner, R. G. (1990). Images of the future now: Autonomy, professionalism, and efficacy (Doctoral dissertation, Fordham University, 1990). Dissertation Abstracts International, 52 (03A), 0776.Wilson, 1993).

Wiersma, W. (2000). Research methods in education: An introduction. Needham Heights, MA:A Pearson. 